Copyright (C 2014 IEEE. Personal use of this material is permitted. Permission from IEEE must be obtained for all other uses, in any current or future media, including reprinting/republishing this material for advertising or promotional purposes, creating new collective works, for resale or redistribution to servers or lists, or reuse of any copyrighted component of this work in other works. 


\section{Stability Assessment of a Small Islanded Power Network with High Penetration of Renewable Energy}

\author{
Dimple Verma \\ Member, Engineers Australia \\ WA, Australia
}

\author{
Dr Sumedha Rajakaruna \\ Department of Electrical and \\ Computer Engineering \\ Curtin University \\ Bentley, WA, Australia
}

\author{
Dr Tim Johnson \\ Jacobs Engineering Group \\ Perth, WA, Australia
}

\begin{abstract}
Electricity generation using renewable energy sources especially wind and solar photovoltaic is increasing rapidly and replacing fossil generation. The impact is more significant in small islanded networks which historically have relied on diesel engines for generation. Since wind and photovoltaic generation is intermittent and unpredictable, it becomes difficult to schedule and manage a small network with varying load demand. Therefore, conventional generation or some kind of energy storage is required to maintain the balance between total network generation and load demand. This paper presents a case study of a small islanded electrical network in Western Australia with various combinations of wind turbines, photovoltaic modules and diesel generators. It studies their impact on voltage and frequency stability of the network with a view to maximize the penetration of renewable energy.
\end{abstract}

Index Terms-Renewable energy sources, wind energy, solar energy, Photovoltaic system, Stability analysis

\section{INTRODUCTION}

Most islanded and remote power networks around the world are dependent on fossil fuels, typically diesel oil, for power generation. These networks are exposed to diesel fuel price volatility and high operation and maintenance costs including fuel transportation and bulk storage. Renewable energy sources such as wind and solar photovoltaic (PV) are clean, affordable, readily available, sustainable and can supplement generators in both grid connected and off grid residential and commercial applications. Hybrid energy systems integrate these renewable energy technologies with diesel generators (DGs), inverters and batteries to provide grid quality power in remote areas not connected to a utility grid.

An existing small power system of Laverton in Western Australia is used as a test case to investigate both voltage and frequency stability with the maximum penetration of wind and solar PV generation.

A review of literature in this area is presented in section II. The proposed method for load-generation analysis and dynamic studies are presented in section III and section IV respectively. Section V presents a case study of small islanded network in Western Australia. The conclusion of the proposed method is presented in section VI.

\section{LITERATURE REVIEW}

The stability problem with high penetration of renewable energy in the power network is a known issue and several researches have been conducted in this area.

Mai H. Nguyen, et.al. [1] and Tareq Aziz et.al. [2] focused on voltage and small signal stability of a power system with the increase in the penetration level of renewable energy and diverse power generation portfolios. The study shows that increase in wind energy dispatch, caused by the increase in wind speed, reduces the damping ratio. However, increase in penetration level of wind turbines with permanent magnet generators slightly improves the damping of inter-area mode. The paper suggests $20 \%$ to $30 \%$ renewable energy (in MW) penetration in the test system as a preferred penetration, which provides reasonable loadability and optimal grid losses.

R.H. Kemsley et.al. [3] demonstrates the integration of hydro generation with the inverter systems to achieve very low carbon electricity supply for communities and outline the issues associated with implementing such systems. The issues identified in the paper are as below:

- Use of multiple renewable energy sources helps to accommodate seasonal output variation and minimise fuel consumption.

- System with multiple generation sources require more maintenance than networks supplied from a grid or from a single generator

- Battery energy storage is a key component of the systems. However, cost and space requirement often limit battery storage;

- Meeting statutory network operating standards in small power systems is achievable but may require careful and innovative design

Frequency control with high penetration of renewables is discussed in a paper presented by Pieter et.al [4]. The study shows that the frequency support deteriorates by integration of 
renewables in the generation mix but can be improved through additional controls such as energy storage system, de-loading of wind turbine / solar PV, kinetic energy support from the wind turbine and load-side management. The control of an inertia-less grid is also described in this paper. The paper conclude that the effect of the penetration of renewable is most noticeable during low load situations as the use of renewable generation will cause the deactivation of traditional power plants and consequently lower the overall grid inertia.

The paper by Nayar [5] presents case studies of micro-grid distributed generation systems using wind turbines, photovoltaic modules and details on how an innovative variable speed diesel generator can be integrated into such systems. The study indicates that the newly developed variable speed diesel generator system is expected to provide good opportunity to showcase high penetration of renewable energies using state-of-the-art wind turbines and photovoltaic modules.

Neven et.al.[6] indicates that due to high energy costs in the small islands prove to be excellent test beds for the introduction of renewable energy technologies. The paper describes the H2RES model for optimisation of integration of hydrogen usage with intermittent renewable energy sources on the isolated island. The H2RES model includes reversible hydro and batteries as storage technologies with the renewable energy sources.

As noted above, several papers describe various issues with high renewable penetration in a small islanded network. This paper has considered a transient stability studies for a practical power systems network to identify the maximum possible renewable energy penetration on a small islanded network in Western Australia.

\section{LOAD-GENERATION ANALYSIS}

The load-generation analysis provides a guideline to the optimal installed capacity for the renewable energy sources. The guideline presented in this paper includes generation from wind energy source and solar PV.

The first step in this analysis is to identify network load demand for a particular network. The network load demand varies with the time and generally be available for a year in the form of historical records. In certain cases, the demand can also be predicted for the future study years based on the historical load data.

To meet the load demand, the installed capacity of generation needs to be higher than the maximum load at any point of time. In case of renewable generation, the generation at any point of time depends on the available energy sources (wind and solar) at that point of time and the installed capacity of the renewable sources. A typical daily load-generation curve for an installed renewable generation is shown in Fig.1.

As shown in the Fig.1, the total renewable energy generation is higher than the total load demand during 06:00 hrs to 09:00 hrs and for rest of the hours, total renewable generation was lower than the total load demand. This shows a requirement of energy storage for 06:00 to 09:00 hours and conventional energy generation to be in service for most of the day.

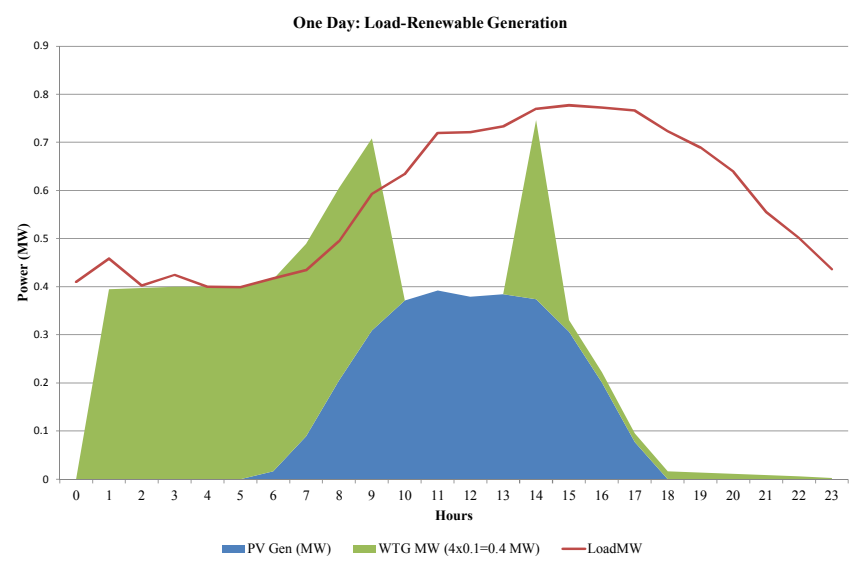

Figure 1. Daily load-generation curve

The installed capacity of each renewable source can be optimised by load-generation analysis. The load-generation analysis aims to reduce the diesel energy throughout a year with a different mix of solar and wind energy. The optimal wind and solar generation can be derived using the below equation, which is a minimization of diesel generation:

$\operatorname{Minimise} \sum_{\mathrm{i}=1}^{8760} \mathrm{G}_{\mathrm{D}}^{\mathrm{i}}=\sum_{\mathrm{i}=1}^{8760}\left(\mathrm{~L}^{\mathrm{i}}-\mathrm{G}_{\mathrm{W}}^{\mathrm{i}}-\mathrm{G}_{\mathrm{S}}^{\mathrm{i}}\right)$

Where;

$\mathrm{L}^{\mathrm{i}}=$ Loadat $\mathrm{i}^{\text {th }}$ hour

$\mathrm{G}_{\mathrm{D}}^{\mathrm{i}}=$ Dieselgeneration at $\mathrm{i}^{\text {th }}$ hour

$\mathrm{G}_{\mathrm{W}}^{\mathrm{i}}=$ Wind generation at $\mathrm{i}^{\text {th }}$ hour,

$=$ function of wind installed capacity and wind speed at $i^{\text {th }}$ hour

$\mathrm{G}_{\mathrm{S}}^{\mathrm{i}}=$ Solar PV generation at $\mathrm{i}^{\text {th }}$ hour

$=$ function of solar installed capacity and solar radiation at $\mathrm{i}^{\text {th }}$ hour

A set of curves with combination of wind and solar installed capacity can be plotted to identify the required mix of generation which can present a maximum displacement of diesel generation in a load year.

\section{DYNAMIC STUDIES}

The load-generation provides a maximum possible renewable generation in the network. The network stability with these generation mix needs to evaluate against the network operating criteria. To identify the network stability for different network disturbance, the system dynamic model needs to be developed in a power system simulation software program.

The dynamic models for diesel generators are to include an automatic voltage regulator with exciter and a governor system. A suitable dynamic model for the solar PV inverter and wind turbine is required. These dynamic models are to be included in the system simulation model. The network load is 
to be represented with an appropriate voltage and frequency dependent load models.

The network dynamic stability can be assessed in terms of system frequency and bus voltages. The network frequency is required to remain with the specified range during and after a disturbance. Similarly, the voltage at each customer end also required to remain within the stability limit. Generally, these limits are specified in the respective network technical codes for a stable network operation.

Several network disturbances are required to be simulated on the developed network. A typical set of network disturbances are listed below:

- Loss of a portion of the wind turbine generation (WTG) due to wind variability

- Loss of a portion of solar PV output due to moving clouds

- Sudden tripping of a single wind turbine or solar PV inverter due to internal or external fault

- Sudden tripping of a diesel generating unit

- Network faults

For each of the above disturbance, the bus frequency and voltage is to be monitored and system stabilityis to be assessed accordingly.

The complete network modeling, simulation of above mentioned disturbance events and monitoring of the above mentioned variables can be done using any suitable power system simulation software. The modeling software is required to have features for dynamic modeling of renewable energy sources.

\section{CASE Study}

To identify the network stability with the maximum penetration of renewable energy sources in an electric network of Laverton was used in this study. Laverton is a town located in Western Australia and has a maximum load demand of 1.2 MW in 2013 and expected to observe a maximum load of 1.9 MW in 2020. The simplified network diagram of this network is shown Fig. 2

To assess the possibility of maximum renewable penetration in the network, the PV solar output was calculated for the entire year (for each hour). The PV generation profile was considered, based on the past records from one of the solar farm [7] in Western Australia. The daily power generation record for the past one year was provided by Independent Market Operator (IMO) [8] for this study. The record provides a sufficient reflection of solar radiation pattern including a change in solar PV generation due to daily cloud movements. To get the wind generation in the Laverton, wind speed records were collected from the Bureau of Metrology [9]. These records were then extrapolated for hourly records. The extrapolation was based on the linear relation between the two given points.

An optimisation of solar PV and wind generation was performed with various combinations of solar PV and wind generation installed capacities. For each of the installed renewable generation, energy displaced from diesel generation was calculated.The energy displaced for each of the solar PV and wind generation scenarios is presented in Fig. 3 and Fig. 4. As shown in these figures, the maximum diesel generation energy is displaced in 2013 when the system includes $0.8 \mathrm{MW}$ PV solar plus + 0.4 MW wind installed capacity. In 2020 the maximum displacement occurs with 1.3 MW PV solar plus $0.7 \mathrm{MW}$ wind installed capacity.

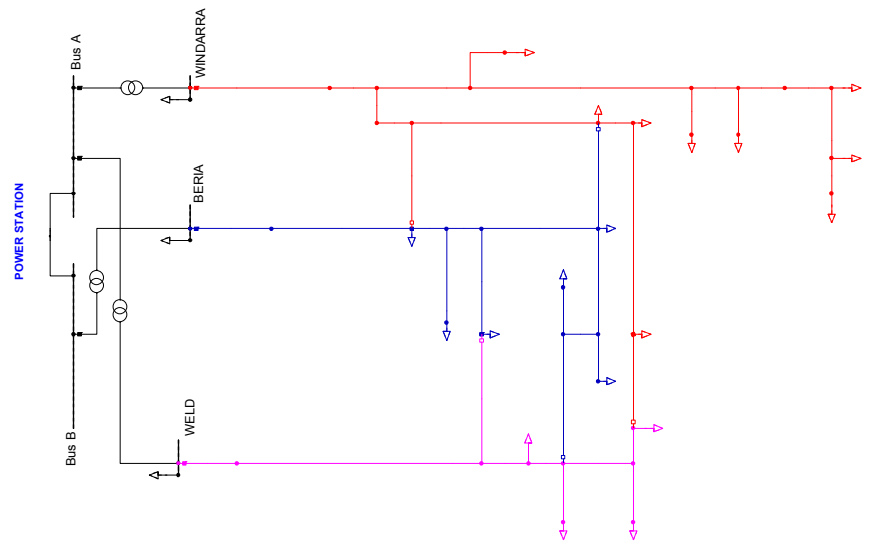

Figure 2. Single line diagram of Laverton electric network

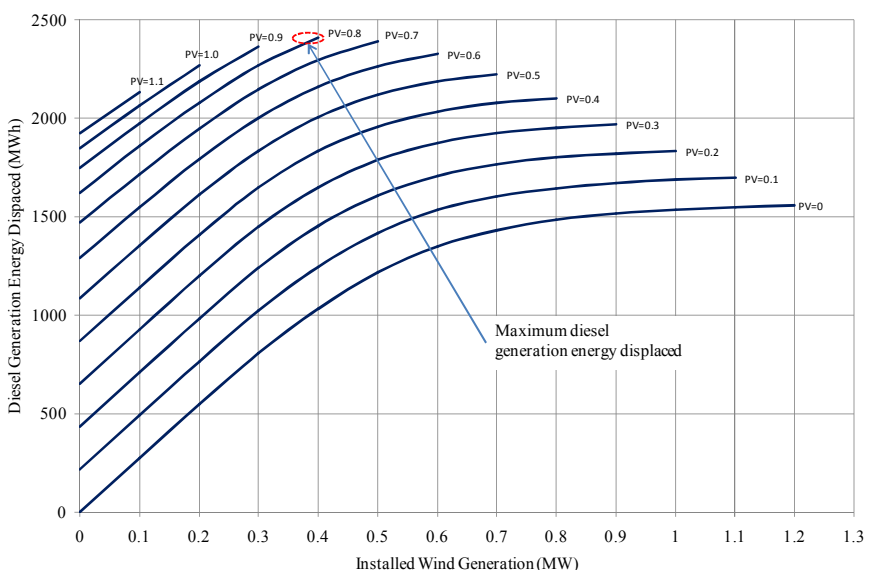

Figure 3. Diesel generation energy displaced vs. renewable generation penetration for 2013 load scenario

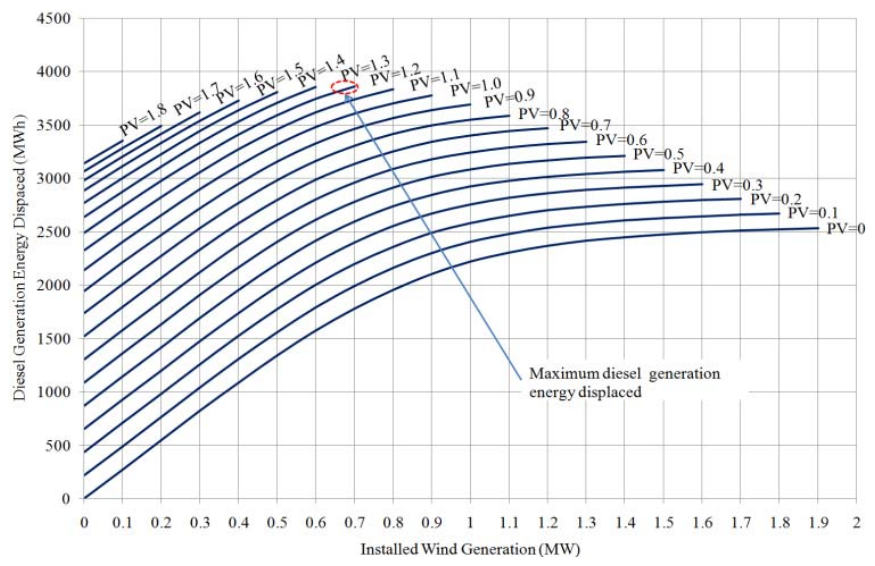

Figure 4. Diesel generation energy displaced vs. renewable generation penetration for 2020 load scenarion 
The network dynamic model was developed based on the standard IEEE dynamic models and library models available in power systems simulation software DIgSILENT PowerFactory [10]. These models includes diesel generator controls (automatic voltage regulator and governor), wind turbine and solar PV inverter models.

The study cases in the PowerFactory model were setup for the 2013 and 2020 network load scenarios along with different level of renewable generation. The cases as setup in the PowerFactory model are shown in TABLE I.

TABLE I. DYNAMIC STUDY CASES

\begin{tabular}{|c|c|c|c|c|c|c|}
\hline $\begin{array}{c}\text { Case } \\
\text { Id }\end{array}$ & $\begin{array}{l}\text { Load } \\
\text { (MW) }\end{array}$ & DG & $\begin{array}{c}\text { DG } \\
\text { Spinning } \\
\text { Reserve } \\
\text { (MW) }\end{array}$ & $\begin{array}{l}\text { WTG } \\
\text { (MW) }\end{array}$ & $\begin{array}{c}\text { Solar } \\
\text { PV } \\
\text { (MW) }\end{array}$ & $\begin{array}{c}\text { Total } \\
\text { Renewable } \\
\text { Energy } \\
\text { (\% of total } \\
\text { generation) }\end{array}$ \\
\hline $2013-0$ & 1.2 & $\begin{array}{c}0.0 \mathrm{MW} \\
(1 \mathrm{DG} \text { On })\end{array}$ & 0.35 & 0.4 & 0.8 & 100 \\
\hline 2013-1 & 1.2 & $\begin{array}{c}0.2 \mathrm{MW} \\
(2 \mathrm{DG} \text { On) }\end{array}$ & 0.50 & 0.2 & 0.8 & 83 \\
\hline $2013-2$ & 1.2 & $\begin{array}{c}0.4 \mathrm{MW} \\
(2 \mathrm{DG} \text { On) }\end{array}$ & 0.30 & 0.0 & 0.8 & 67 \\
\hline 2013-3 & 1.2 & $\begin{array}{c}0.4 \mathrm{MW} \\
(2 \mathrm{DG} \text { On) }\end{array}$ & 0.30 & 0.4 & 0.4 & 67 \\
\hline 2013-4 & 1.2 & $\begin{array}{c}0.8 \mathrm{MW} \\
(4 \mathrm{DG} \text { On) }\end{array}$ & 0.60 & 0.4 & 0.0 & 33 \\
\hline $2020-0$ & 1.9 & $\begin{array}{c}0.0 \mathrm{MW} \\
(1 \mathrm{DG} \text { On) }\end{array}$ & 0.35 & 0.7 & 1.2 & 100 \\
\hline $2020-1$ & 1.9 & $\begin{array}{c}0.35 \mathrm{MW} \\
\text { (2 DG On) }\end{array}$ & 0.35 & 0.35 & 1.2 & 82 \\
\hline $2020-2$ & 1.9 & $\begin{array}{c}0.7 \mathrm{MW} \\
\text { (3 DG On) }\end{array}$ & 0.35 & 0.0 & 1.2 & 63 \\
\hline $2020-3$ & 1.9 & $\begin{array}{c}0.6 \mathrm{MW} \\
\text { (3 DG On) }\end{array}$ & 0.45 & 0.7 & 0.6 & 68 \\
\hline $2020-4$ & 1.9 & $\begin{array}{c}1.2 \mathrm{MW} \\
\text { (5 DG On) }\end{array}$ & 0.55 & 0.7 & 0.0 & 37 \\
\hline
\end{tabular}

The list of disturbances and their description is listed TABLE II.

TABLE II. DYNAMIC STUDy EVENTS

\begin{tabular}{|l|l|}
\hline $\begin{array}{l}\text { Event } \\
\text { Id }\end{array}$ & Event Description \\
\hline Event-1 & $\begin{array}{l}\text { Network load increased by 10\%over a second: } \\
\text { This event is to demonstrate the system stability for the } \\
\text { sudden increase in the load, also observed in the load curve } \\
\text { analysis. A load ramp event was applied in PowerFactory } \\
\text { which ramps the load by 10\% in 1.0 seconds. }\end{array}$ \\
\hline Event-2 & $\begin{array}{l}\text { PV solar generation at one location reduced by 50\%: } \\
\text { PV solar generation is impacted by moving clouds. To } \\
\text { demonstrate the impact of moving clouds, the generation at } \\
\text { one location is reduced to 50\% of its initial value. In } \\
\text { PowerFactory, this event was simulated as reduction in } \\
\text { modelled sources dc current. }\end{array}$ \\
\hline Event-3 & $\begin{array}{l}\text { Tripping of one wind turbine out of four: } \\
\text { It is expected that any of the wind turbines in the network can } \\
\text { trip due to any disturbance in the network or in the wind } \\
\text { turbine generator system. To model this event in } \\
\text { PowerFactory, a wind turbine circuit breaker was turned off. }\end{array}$ \\
\hline Event-4 & $\begin{array}{l}\text { One diesel generator tripped: } \\
\text { This event is similar to the above event. One of the diesel } \\
\text { generators which were in service was turned off to simulate } \\
\text { this event. }\end{array}$ \\
\hline
\end{tabular}

To assess the system stability, system frequency and bus voltages were recorded during the simulations. Following stability limits were considered for stable operation of the network:

- As per the utility technical rules, the system can operate without load shedding for a frequency down to $49.0 \mathrm{~Hz}$. Therefore, a minimum frequency of 49.0 $\mathrm{Hz}$ was used as the stability criteria.

- After a disturbance in the network, if the system voltage does not recover to within 0.9 to $1.1 \mathrm{pu}$ then it will be considered as unstable operation.

Each of the above mentioned study scenarios were tested for the listed events as above. The summary of system minimum frequencies recorded during the simulation is shown in TABLE III. Those events with frequency reductions below $49.0 \mathrm{~Hz}$ are grey shaded. The system voltage in all the studied cases recovers to the nominal operating voltage range and does not impose any instability issues. However, in 2020 study case the reactive power requirement was higher than the available reactive generation sources. To meet the additional reactive power, a $125 \mathrm{kVAR}$ capacitor at each feeder was connected.

TABLE III. FREQUENCY FOR THE SIMULATED EVENTS

\begin{tabular}{|c|c|c|c|c|}
\hline Case Id & Event-1 & Event-2 & Event-3 & Event-4 \\
\cline { 1 - 4 } $2013-0$ & 49.2 & 48.4 & 49.1 & $\mathrm{a}$ \\
\hline $2013-1$ & 49.5 & 49.4 & 49.6 & 49.7 \\
\hline $2013-2$ & 49.4 & 49.1 & $\mathrm{~b}$ & 48.5 \\
\hline $2013-3$ & 49.4 & 49.1 & 49.4 & $\mathrm{~d}$ \\
\hline $2013-4$ & 49.6 & $\mathrm{c}$ & 49.6 & 49.1 \\
\hline $2020-0$ & 49.4 & 48.1 & 49.1 & $\mathrm{a}$ \\
\hline $2020-1$ & 49.3 & 48.7 & 49.2 & 48.9 \\
\cline { 1 - 2 } $2020-2$ & 49.4 & 49.1 & $\mathrm{~b}$ & 48.8 \\
\cline { 1 - 2 } $2020-3$ & 49.4 & 49.1 & 49.3 & 48.9 \\
\hline $2020-4$ & 49.6 & $\mathrm{c}$ & 49.5 & 49.2 \\
\hline
\end{tabular}

a. Event-4 (tripping of DG) for case '2013-0' and case '2020-0' is not applicable, as these cases has only one DG in service.

b. Event-3 (tripping of WTG) for case '2013-2' and case '2020-2' is not applicable, as these cases are without WTG.

c. Event-2 (tripping of solar PV) for case '2013-4' and case '2020-4' is not applicable, as these cases are without solar PV.

d. he simulation did not proceed as there is not enough generation after executing of Event-4 (tripping of DG) for case '2013-3'.

For the load increment event (i.e. Event-1), all the cases were able to meet the stability requirements. The $10 \%$ load increment event presents $0.12 \mathrm{MW}$ and $0.19 \mathrm{MW}$ in 2013 and 2020 cases respectively. The increase in load was well within the available spinning reserve and hence the frequency did not reach below the stability limit of $49.0 \mathrm{~Hz}$. For the reduction in PV generation (i.e. Event-2), the system was frequency unstable for Case '2013-0', Case '2020-0' and Case '2020-1'. 
For the wind turbine trip event (i.e. Event-3), the system frequency was within the required limit for all the cases. The system frequency for diesel generator trip event (i.e. Event-4) was below the required limit for case '2013-2' and all cases in 2020 except for one case '2020-4'. All the stable cases have higher spinning reserve as compare to frequency unstable cases.

Additional diesel generation will be required to maintain system stability. The comparison of system frequency before and after additional diesel generator in one of the studied case is shown in Fig. 5.

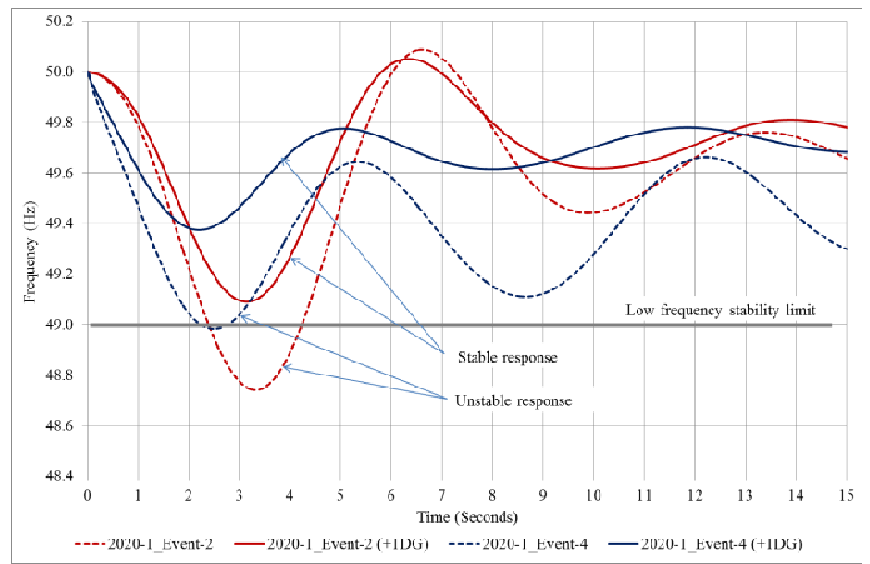

Figure 5. Comparison of system frequency before and after additional diesel generator (2020-1, Event-2 and Event-4)

The minimum numbers of diesel generators required to maintain system frequency stability for the simulated events are listed in TABLE IV. A minimum of two diesel generators are required in 2013 with the maximum renewable generation while a minimum of three diesel generators are required in the 2020 load scenario with maximum renewable generation.

TABLE IV. STABLE OPERATION WITH RENEWABLE GENERATION

\begin{tabular}{|c|c|c|c|c|c|}
\hline Case Id & $\begin{array}{c}\text { Load } \\
\text { (MW) }\end{array}$ & DG & $\begin{array}{c}\text { DG } \\
\text { Spinning } \\
\text { Reserve } \\
\text { (MW) }\end{array}$ & $\begin{array}{c}\text { WTG } \\
\text { (MW) }\end{array}$ & $\begin{array}{c}\text { Solar } \\
\text { PV } \\
\text { (MW) }\end{array}$ \\
\hline 2013-0 & 1.2 & 0.0 MW (2 DG On)* & 0.70 & 0.4 & 0.8 \\
\hline $2013-1$ & 1.2 & 0.2 MW (2 DG On) & 0.50 & 0.2 & 0.8 \\
\hline $2013-2$ & 1.2 & 0.4 MW (3 DG On)* & 0.65 & 0.0 & 0.8 \\
\hline $2013-3$ & 1.2 & 0.4 MW (2 DG On) & 0.30 & 0.4 & 0.4 \\
\hline $2013-4$ & 1.2 & 0.8 MW (4 DG On) & 0.60 & 0.4 & 0.0 \\
\hline $2020-0$ & 1.9 & 0.0 MW (3 DG On)* & 1.05 & 0.7 & 1.2 \\
\hline $2020-1$ & 1.9 & 0.35 MW (3 DG On)* & 0.70 & 0.35 & 1.2 \\
\hline $2020-2$ & 1.9 & 0.7 MW (4 DG On)* & 0.70 & 0.0 & 1.2 \\
\hline $2020-3$ & 1.9 & 0.6 MW (4 DG On)* & 0.80 & 0.7 & 0.6 \\
\hline $2020-4$ & 1.9 & 1.2 MW (5 DG On) & 0.55 & 0.7 & 0.0 \\
\hline * Additional diesel generator was switched ON to maintain frequency stability &
\end{tabular}

The studied presents the maximum renewable energy mix with minimum diesel generation required to maintain system frequency stability in the network. A minimum of two diesel generators will be required to maintain frequency stability in 2013 and a minimum three diesel generators will be required to maintain frequency stability in 2020 along with the above mentioned maximum renewable generation.

\section{CONCLUSION}

A power network of Laverton in Western Australia was selected for the study. This network is currently supplied by diesel generators and has potential to include renewable energy sources.

The load analysis of the network suggests that for 2013 load scenario, which is $1.2 \mathrm{MW}$, the maximum displacement of diesel generation energy occurs with $0.4 \mathrm{MW}$ wind and 0.8 MW of solar. For the 2020 load scenario, which 1.9 MW, the maximum displacement is occurs with $0.7 \mathrm{MW}$ wind and 1.2 MW solar energy sources. The simulated results of dynamic analysis suggest that the frequency cannot be within the required limit for the simulated disturbances in some of the cases. The events which were found to be stable were mainly where the large amount of diesel generation was in service. A further analysis suggests that the system can be stable if additional diesel generator/generators is/are kept in service. The additional diesel generators will provide more spinning reserve.

The study concludes that the maximum penetration of renewable energy is limited by system stability which can be maintained by spinning reserve in the form of diesel generators.

\section{ACKNOWLEDGMENT}

The authors wish to express their sincere gratitude to David Stephens, Horizon Power, WA, Australia, for his support to the work reported in the paper.

\section{REFERENCES}

[1] Mai H. Nguyen, Tapan K. Saha, Mehdi Eghbal, Impact of high level of renewable energy penetration on inter-area oscillation, Australasian University Power Engineering Conference, 29 September - 3 October 2013.

[2] Tareq Aziz, SudarshanDahal, N. Mithulananthan, Tapan K. Saha, Impact of widespread penetrations of renewable generation on distribution system stability, $6^{\text {th }}$ International Conference on Electrical and Computer Engineering, ICECE 2010, 18-20 December 2010, Dhaka, Bangladesh.

[3] R.H. Kemsley, P. McGarley, S. Wade, F. Thim, Making small highpenetration renewable energy systems works Scottish Island Experience, http://www.senergyworld.com/media-centre/publications.

[4] Pieter Tielens, Dirk Van Hertem, Grid inertia and frequency control in power systems with high penetration of renewables, https://irias.kuleuven.be/bitstream/123456789/345286/1/Grid_Inertia and_Frequency_Control_in_Power_Systems_with_Hig

[5] Chemmangot V. Nayar, High renewable energy penetration diesel generator systems, Paths to Sustainable Energy, Dr Artie Ng (Ed.), ISBN: 978-953-307-401-6, InTech, Available from: http://cdn.intechopen.com/pdfs-wm/12530.pdf 
[6] Neven Duic', Maria da GracaCarvalho, Increasing renewable energy sources in island energy supply: case study Porto Santo, Elsevier, Renewable \& Sustainable Energy Review, November 2003.

[7] Greenough River Solar Farm, http://www.greenoughsolarfarm.com.au/

[8] Independent Market Operator of Western Australia, http://www.imowa.com.au/

[9] Beureu of metrology website, http://www.bom.gov.au/climate/data/index.shtml?bookmark=200\&vie $\underline{w}=$ map

[10] DIgSILENT PowerFactory, power systems simulation software, http://www.digsilent.de/ 